\title{
Analysis of Kinetics of Diffusion Induced Recrystallization in Fe Phase of $\mathrm{Cu} / \mathrm{Fe} / \mathrm{Cu}$ Diffusion Couples
}

\author{
Yasuhiko KAWANAMI, Masanori KAJIHARA ${ }^{1)}$ and Tsutomu MORI ${ }^{2)}$
}

Graduate Student, Tokyo Institute of Technology, Nagatsuta, Midori-ku, Yokohama, Kanagawa-ken, 226 Japan. 1) Department of Materials Science and Engineering, Tokyo Institute of Technology, Nagatsuta, Midori-ku, Yokohama, Kanagawa-ken, 226 Japan. $\quad 2$ ) Formerly Department of Materials Science and Engineering, Tokyo Institute of Technology. Now at Ryobi Ltd., Toshima, Kita-ku, Tokyo, 114 Japan.

(Received on March 24, 1997; accepted in final form on May 16, 1997)

\begin{abstract}
Combining the columnar-geometry and boundary-diffusion model by $\mathrm{Li}$ and Hillert with the energy balance model by Kajihara and Gust, a new kinetic equation has been obtained to describe the growth rate of the alloyed region due to diffusion induced recrystallization (DIR) in a solution phase of binary systems. The equation has been utilized to analyze quantitatively the kinetics of DIR in the $\mathrm{Fe}(\mathrm{Cu})$ system observed by the present authors using $\mathrm{Cu} /(\mathrm{Fe}-4.8$ mass\%)/ $\mathrm{Cu}$ diffusion couples. The notation $\mathrm{Fe}(\mathrm{Cu})$ means that $\mathrm{Cu}$ atoms diffuse into a pure $\mathrm{Fe}$ or binary $\mathrm{Fe}-\mathrm{Cu}$ phase. The observations indicate that the thickness $l$ of the DIR region formed in the Fe phase from each interface increases with increasing annealing time $t$ according to the relationship $l=1.58 \times 10^{-6}\left(t / t_{0}\right)^{0.29}$ at $1323 \mathrm{~K}$. Here, $l$ and $t$ are measured in $\mathrm{m}$ and $\mathrm{s}$, respectively, and $t_{0}$ is unit time, $1 \mathrm{~s}$. Using the mobility $M$ as the fitting parameter of the kinetic equation, we have obtained the value of $M=8.64 \times 10^{-13} \mathrm{~m}^{4} / \mathrm{J} \mathrm{s}$ and the relationship $l=$ $1.08 \times 10^{-6}\left(t / t_{0}\right)^{0.33}$ on the basis of the observations. Through the analysis, it is concluded that $l$ increases in proportion to $\sqrt{t}$ for DIR in a pure metal whereas $l$ increases proportionately with $\sqrt[3]{t}$ for DIR in a solution phase even with a low solute concentration.
\end{abstract}

KEY WORDS: diffusion induced recrystallization; Fe-Cu system; grain boundary migration; grain boundary diffusion.

\section{Introduction}

A series of studies on diffusion induced recrystallization (DIR) in the $\mathrm{Fe}(\mathrm{Cu})$ and $\mathrm{Ni}(\mathrm{Cu})$ systems have been being carried out by the present authors using $\mathrm{Cu} / \mathrm{Fe} / \mathrm{Cu}$ and $\mathrm{Cu} / \mathrm{Ni} / \mathrm{Cu}$ diffusion couples consisting of pure $\mathrm{Cu}$ single crystals and $\mathrm{Fe}$ and $\mathrm{Ni}$ polycrystalline specimens. ${ }^{1-4)}$ DIR is the phenomenon that new grains with different solute concentrations are produced behind moving grain boundaries owing to recrystallization combined with diffusion of solute atoms along the moving boundaries. On the contrary, during diffusion induced grain boundary migration (DIGM), a region with different composition is left behind a moving grain boundary due to grain boundary migration combined with the diffusion of solute atoms along the moving boundary. Here, the notation $A(B)$ means that a solute $\mathrm{B}$ diffuses into a pure metal $\mathrm{A}$ or a binary $\mathrm{A}-\mathrm{B}$ alloy according to convention. As to the $\mathrm{Fe}(\mathrm{Cu})$ system, the $\mathrm{Cu} / \mathrm{Fe} / \mathrm{Cu}$ and $\mathrm{Cu} /(\mathrm{Fe}-4.8 \mathrm{Cu}) / \mathrm{Cu}$ diffusion couples were annealed at 1193 and $1323 \mathrm{~K}$ for various times between $3.0 \times 10^{2}$ and $8.6 \times 10^{4} \mathrm{~s}^{11}$ In this experiment, DIR was clearly observed to occur only in the Fe phase of the $\mathrm{Cu} /(\mathrm{Fe}-4.8 \mathrm{Cu}) / \mathrm{Cu}$ diffusion couples annealed at $1323 \mathrm{~K}$. The DIR regions alloyed with $\mathrm{Cu}$ are formed in the Fe phase from the interfaces of the diffusion couple and grow toward the center of the Fe phase. The observations of the $\mathrm{Cu} /(\mathrm{Fe}-4.8 \mathrm{Cu}) / \mathrm{Cu}$ diffusion couples indicate that the thickness $l$ of the DIR region increases with increasing annealing time $t$ according to the relationship $l=1.58 \times 10^{-6}\left(t / t_{0}\right)^{0.29}$ at $1323 \mathrm{~K}$. Here, $l$ and $t$ are measured in $\mathrm{m}$ and $\mathrm{s}$, respectively, and $t_{0}$ is unit time, $1 \mathrm{~s}$. Due to DIR, the penetration of $\mathrm{Cu}$ in the $\mathrm{Fe}$ phase occurs at rates two orders of magnitude greater than the one evaluated from the volume diffusion.

DIR in the $\mathrm{Fe}(\mathrm{Zn})$ system was experimentally studied by $\mathrm{Li}$ and Hillert using polycrystalline pure $\mathrm{Fe}$ specimens zincified at 733 to $923 \mathrm{~K}$ by a capsule zincification technique. ${ }^{5)}$ In their experiment, the DIR region alloyed with $\mathrm{Zn}$ is formed from the surface of the pure $\mathrm{Fe}$ specimen and grows into the specimen. They also theoretically analyzed the observations and then obtained a kinetic equation to describe the growth rate of the DIR region as a function of the annealing time combining the chemical driving force model by Hillert and Purdy ${ }^{6)}$ with their own columnar-geometry and boundary-diffusion model. The combined model is hereafter called Li-Hillert model. According to the Li-Hillert model, the thickness $l$ of the DIR region increases in proportion to the annealing time $t$ at early stages of the reaction, whereas $l$ increases proportionately with the square root of $t$ at late stages of the reaction. This 
model seems to explain quantitatively their observations on DIR in the $\mathrm{Fe}(\mathrm{Zn})$ system. However, the relationship $l=1.58 \times 10^{-6}\left(t / t_{0}\right)^{0.29}$ obtained by the present authors for $\mathrm{DIR}$ in the $\mathrm{Cu} /(\mathrm{Fe}-4.8 \mathrm{Cu}) / \mathrm{Cu}$ diffusion couple indicates that $l$ increases in proportion to the almost cubic root of $t$. This kinetic behavior of DIR cannot be accounted for by the Li-Hillert model.

In the Li-Hillert model, the chemical driving force of the grain boundary migration is evaluated for DIR where the alloyed region grows into a pure metal. On the other hand, the alloyed region is formed in a binary $\mathrm{Fe}-\mathrm{Cu}$ solution phase for DIR in the $\mathrm{Cu} /(\mathrm{Fe}-4.8 \mathrm{Cu}) / \mathrm{Cu}$ diffusion couple. It was pointed out by Kajihara and Gust $^{7)}$ that the chemical driving force for the formation of the alloyed region due to DIR or DIGM remarkably decreases with increasing concentration of a solute in an untransformed matrix. The difference between the compositions of the untransformed matrices in the $\mathrm{Fe}(\mathrm{Zn})$ and $\mathrm{Fe}(\mathrm{Cu})$ systems may be the reason why the kinetic behavior of DIR observed by the present authors using the $\mathrm{Cu} /(\mathrm{Fe}-4.8 \mathrm{Cu}) / \mathrm{Cu}$ diffusion couples is different from the one of DIR reported by $\mathrm{Li}$ and Hillert for zincified $\mathrm{Fe}$ specimens. In this work, a new kinetic equation has been proposed to describe the relationship between the thickness of the alloyed region and the annealing time for DIR which occurs in a binary solution phase. The energy balance model by Kajihara and Gust ${ }^{8)}$ has been combined with the columnar-geometry and boundary-diffusion model by $\mathrm{Li}$ and Hillert. ${ }^{5)}$ The equation has been utilized to analyze quantitatively the kinetic behavior of DIR observed by the present authors in the $\mathrm{Fe}$ phase of the $\mathrm{Cu} /(\mathrm{Fe}-4.8 \mathrm{Cu}) / \mathrm{Cu}$ diffusion couple. ${ }^{1)}$

\section{Model}

Let us consider the substitutional binary A-B system in which the A-rich and B-rich solid solution phases, $\alpha$ and $\beta$ respectively, equilibrate with each other. Now, an $\alpha / \beta$ diffusion couple is annealed at an appropriate

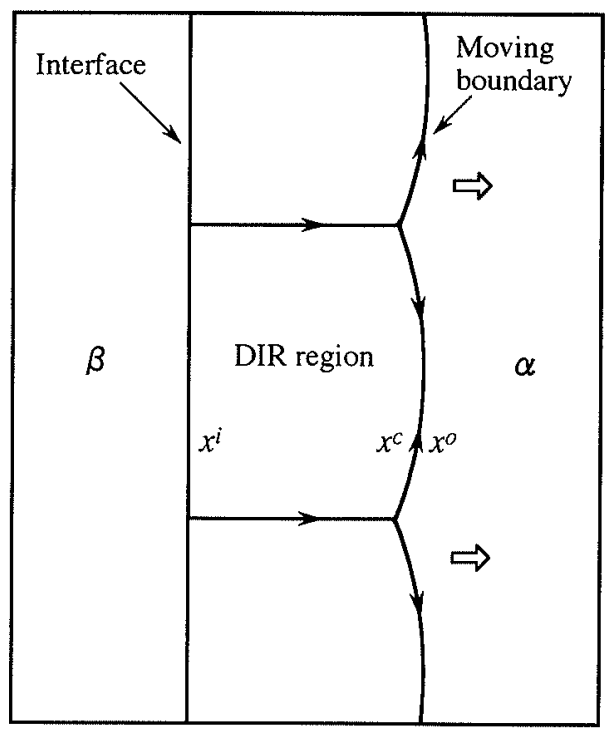

Fig. 1. Schematic diagram of fine grains formed in the $\alpha$ phase from the interface of the $\alpha / \beta$ diffusion couple in the binary $\mathrm{A}-\mathrm{B}$ system due to DIR. temperature of the $\alpha+\beta$ two-phase equilibrium and then DIR is supposed to take place only in the $\alpha$ phase. During the annealing, fine grains alloyed with the solute $B$ are formed from the interface and grow into the $\alpha$ phase due to DIR as schematically shown in Fig. 1. The migration rate $v$ of the moving grain boundary is usually related to the driving force $\Delta G$ by the equation

$$
v=\frac{\mathrm{d} l}{\mathrm{~d} t}=M \Delta G=M\left(\frac{\Delta G_{\mathrm{m}}}{V_{\mathrm{m}}}\right) .
$$

Here, $l$ is the thickness of the DIR region, $t$ is the annealing time or the reaction time, $M$ is the mobility of the moving grain boundary, and $\Delta G$ has the dimension of force per unit area or energy per unit volume. $\Delta G_{\mathrm{m}}$ and $V_{\mathrm{m}}$ are the molar driving energy and the molar volume, respectively. If $l, t$ and $\Delta G$ are measured in $\mathrm{m}$, $\mathrm{s}$ and $\mathrm{J} / \mathrm{m}^{3}$, respectively, $M$ takes a unit of $\mathrm{m}^{4} / \mathrm{J}$ s. Since many driving-force models are based on a molar Gibbs energy diagram of an alloy system and $\Delta G_{\mathrm{m}}$ can easily be converted to $\Delta G$ by the equation $\Delta G=\Delta G_{\mathrm{m}} / V_{\mathrm{m}}$, it seems suitable to use the molar driving energy $\Delta G_{\mathrm{m}}$ instead of the driving force $\Delta G$ in this work. $\Delta G_{\mathrm{m}}$ is hereafter called merely driving force unless otherwise noted. Using Eq. (1), Li and Hillert ${ }^{5)}$ proposed a kinetics model for DIR in an A(B) system where the solute $B$ diffuses into the pure metal $A$. In this work, the Li-Hillert model has been extended to DIR in an $\mathrm{A}(\mathrm{B})$ system, where the solute $\mathrm{B}$ diffuses into a binary $\mathrm{A}-\mathrm{B}$ solution phase. These models will be described in detail for the reaction shown in Fig. 1.

\subsection{Li-Hillert Model}

It was pointed out by many investigators ${ }^{5-10}$ ) that the difference between the compositions of the growing and untransformed regions plays the most important role for driving a grain boundary to migrate during DIR and DIGM. On the basis of this idea, the chemical driving force model was proposed by Hillert and Purdy. ${ }^{6)}$ Using the Hillert-Purdy model, Li and Hillert ${ }^{5)}$ evaluated the chemical driving force $\Delta G_{\mathrm{m}}^{\mathrm{c}}$ of the grain boundary migration for DIR. When the alloyed DIR region with composition $x^{\mathrm{c}}$ grows into the pure metal $\mathrm{A}$, the chemical driving force $\Delta G_{\mathrm{m}}^{\mathrm{c}}$ for the grain boundary migration is given by the equation

$$
\Delta G_{\mathrm{m}}^{\mathrm{c}}=-R T \ln \left(1-x^{\mathrm{c}}\right),
$$

if the binary A-B solution phase is thermodynamically ideal. Here, the composition $x^{\mathrm{c}}$ shows the mole fraction of the solute B. It should be noted that $\Delta G_{\mathrm{m}}^{\mathrm{c}}$ is a molar value with respect to the pure metal $A$. If $x^{\mathrm{c}}$ is much smaller than unity, Eq. (2) reduces to

$$
\Delta G_{\mathrm{m}}^{\mathrm{c}}=R T x^{\mathrm{c}} .
$$

Equation (3) indicates that $\Delta G_{\mathrm{m}}^{\mathrm{c}}$ increases in proportion to $x^{\mathrm{c}}$ at a constant temperature. If any friction forces are considered to be neglected, $\Delta G_{\mathrm{m}}$ becomes equal to $\Delta G_{\mathrm{m}}^{\mathrm{c}}$ and thus

$$
\frac{\mathrm{d} l}{\mathrm{~d} t}=M\left(\frac{\Delta G_{\mathrm{m}}^{\mathrm{c}}}{V_{\mathrm{m}}}\right)=\frac{M R T x^{\mathrm{c}}}{V_{\mathrm{m}}}
$$

from Eqs. (1) and (3). Thus, the migration rate $\mathrm{d} / / \mathrm{d} t$ 
increases proportionately with the mole fraction $x^{\mathrm{c}}$ under the present conditions.

In order to estimate the rate of supply of the solute B to the moving grain boundary, the shape of each fine grain in the DIR region was considered to be columnar by $\mathrm{Li}$ and Hillert. ${ }^{5)}$ They also assumed that the diffusion coefficient along the moving grain boundary parallel to the interface is much greater than that along the stationary circular grain boundaries normal to the interface. According to these assumptions, they obtained the following equation to describe the rate of supply of the solute B along the circular grain boundaries to the moving grain boundary.

$$
\frac{\mathrm{d} m}{\mathrm{dt}}=-\frac{1}{2} \pi s \delta \frac{D^{\mathrm{b}}}{V_{\mathrm{m}}} \frac{\mathrm{d} x}{\mathrm{~d} y}=\frac{\pi s \delta}{2} \frac{D^{\mathrm{b}}}{V_{\mathrm{m}}} \frac{x^{\mathrm{i}}-x^{\mathrm{c}}}{l}
$$

Here, $m$ is the amount of the solute B supplied to the moving grain boundary, $s$ is the diameter of the columnar fine grain, $D^{\mathrm{b}}$ is the interdiffusion coefficient along the circular grain boundary, $\delta$ is the thickness of the grain boundary, $x^{\mathrm{i}}$ is the mole fraction of the solute $\mathrm{B}$ in the DIR region at the interface, and $y$ is the distance along the moving direction of the grain boundary measured from the interface. In Eq. (5), the concentration profile of the solute $\mathrm{B}$ along the circular grain boundary is considered to be linear and thus $\mathrm{d} x / \mathrm{d} y=\left(x^{\mathrm{c}}-x^{\mathrm{i}}\right) / l$. This holds good if the boundary diffusion occurs sufficiently fast compared with the migration of the grain boundary. The factor $1 / 2$ means that the diffusional flux along the circular grain boundary is shared with the neighboring fine grains. Considering the columnar geometry of the fine grains, we obtain the equation

$$
\frac{\mathrm{d} m}{\mathrm{~d} t}=\pi\left(\frac{s}{2}\right)^{2} \frac{x^{c}}{V_{\mathrm{m}}} \frac{\mathrm{d} l}{\mathrm{~d} t},
$$

which correlates the supply rate $\mathrm{d} m / \mathrm{d} t$ of the solute B with the growth rate $\mathrm{d} l / \mathrm{d} t$ of the DIR region. Combining Eqs. (5) and (6), the following equation is obtained.

$$
\left(x^{\mathrm{c}}\right)^{2}=\frac{2 \delta D^{\mathrm{b}} V_{\mathrm{m}}\left(x^{\mathrm{i}}-x^{\mathrm{c}}\right)}{M R T l s}
$$

For simplicity, Li and Hillert assumed to be $s=l / 2$ and obtained the equation

$$
x^{\mathrm{c}}=\frac{2 x^{\mathrm{i}}}{\left(1+\sqrt{1+\frac{M R T x^{\mathrm{i}} l^{2}}{\delta D^{\mathrm{b}} V_{\mathrm{m}}}}\right)} .
$$

Inserting Eq. (8) into Eq. (4), the following equation is obtained.

$$
\left(1+\sqrt{1+\frac{M R T x^{\mathrm{i}} l^{2}}{\delta D^{\mathrm{b}} V_{\mathrm{m}}}}\right) \frac{\mathrm{d} l}{\mathrm{~d} t}=\frac{2 M R T x^{\mathrm{i}}}{V_{\mathrm{m}}}
$$

This differential equation can be solved in an analytical manner, if the parameters $M, \delta D^{\mathrm{b}}, V_{\mathrm{m}}$ and $x^{\mathrm{i}}$ are kept to be constant during the reaction at a constant temperature. The analytical solution is given as

$$
\tau=2 \lambda+\lambda \sqrt{1+\lambda^{2}}+\ln \left(\lambda+\sqrt{1+\lambda^{2}}\right) .
$$

Here, $\tau$ and $\lambda$ are the normalized reaction time and the normalized thickness of the DIR region, respectively, defined as

$$
\tau=t \frac{4\left(M R T x^{\mathrm{i}} / V_{\mathrm{m}}\right)^{3 / 2}}{\sqrt{\delta D^{\mathrm{b}}}}
$$

and

$$
\lambda=l \sqrt{\frac{M R T x^{\mathrm{i}}}{\delta D^{\mathrm{b}} V_{\mathrm{m}}}} .
$$

Equation (10) gives a mathematical relationship between the thickness $l$ of the DIR region and the reaction time $t$ through Eqs. (11) and (12).

\subsection{Present Model}

According to the Hillert-Purdy model, ${ }^{6)}$ the chemical driving force is evaluated with respect to the initial composition of the untransformed matrix. This model seems to be much more suitable for discontinuous precipitation reactions in substitutional alloy systems than for DIR, because the average composition inside each cell consisting of the precipitate and the transformed matrix is completely the same as the initial composition of the untransformed matrix in the case of the discontinuous precipitation reactions. In the case of DIR, however, the solute B atoms are supplied to the DIR region behind the moving grain boundary by boundary diffusion along the moving and stational grain boundaries whereas the solvent A atoms may not escape from the DIR region. Hence, the total number of atoms in the DIR region increases with increasing concentration of the solute B in this region. Such a situation will actually be realized in an experiment on DIR in the $\mathrm{Fe}(\mathrm{Zn})$ and $\mathrm{Cu}(\mathrm{Zn})$ systems using a capsule zincification technique. Here, $\mathrm{Zn}$ is a volatile solute element with a high vapor pressure whereas $\mathrm{Fe}$ and $\mathrm{Cu}$ are solvent elements with low vapor pressures at a reaction temperature. In the capsule zincification experiment, $\mathrm{Zn}$ atoms are transferred as vapor from a $\mathrm{Zn}$-source alloy with higher $\mathrm{Zn}$ activity to a specimen with lower $\mathrm{Zn}$ activity. Consequently, fine grains alloyed with $\mathrm{Zn}$ will be formed on the surface of the specimen due to DIR under appropriate conditions. Since the vapor pressure of the solvent is low, the solvent atoms cannot escape from the specimen. Thus, the total number of atoms in the DIR region increases. Such a situation may also be realized in the experiment shown in Fig. 1. In this case, the supply of the solute $B$ atoms to the DIR region is fast due to the boundary diffusion along the columnar and moving grain boundaries, whereas that of the solvent A atoms to the $\beta$ phase is very sluggish owing to the volume diffusion in the $\beta$ phase. Therefore, the A atoms hardly escape from the columnar grain boundary and thus from the DIR region. It was pointed out by Kajihara and Gust $^{7,8)}$ and Fournelle ${ }^{9}$ that the contribution of the solute $\mathrm{B}$ atoms to the total number of atoms in the DIR region should be considered for evaluation of the driving force. Considering this contribution, Kajihara and Gust $^{8)}$ proposed the energy balance model which gives the relationship between the chemical driving force and the drag forces for the grain boundary migration due to 
DIR and DIGM. This model gives the chemical driving force for DIR or DIGM with respect to the composition of the alloyed region. In order to obtain a kinetic equation applicable to DIR in a binary solution phase, the energy balance model will be combined with the columnar-geometry and boundary-diffusion model by $\mathrm{Li}$ and Hillert.

When one mole of the DIR region with composition $x^{\mathrm{c}}$ is produced from $\left(x^{\mathrm{c}}-x^{0}\right) /\left(1-x^{0}\right)$ mole of the solute $\mathrm{B}$ atoms and $\left(1-x^{\mathrm{c}}\right) /\left(1-x^{0}\right)$ mole of the binary $\mathrm{A}-\mathrm{B}$ solution phase with composition $x^{0}$, the chemical driving force $\Delta G_{\mathrm{m}}^{\mathrm{c}}$ is described by the following equation according to the energy balance model ${ }^{8)}$

$\Delta G_{\mathrm{m}}^{\mathrm{c}}=R T\left(1-x^{\mathrm{c}}\right)\left\{\ln \frac{\left(1-x^{0}\right)}{\left(1-x^{\mathrm{c}}\right)}+\frac{x^{0}}{\left(1-x^{0}\right)} \ln \frac{x^{0}}{x^{c}}\right\}$,

if the solution phase is again thermodynamically ideal. Assuming that any friction forces can be neglected, we obtain the following equation from Eqs. (1) and (13).

$$
\frac{\mathrm{d} l}{\mathrm{~d} t}=\frac{M R T}{V_{\mathrm{m}}}\left(1-x^{\mathrm{c}}\right)\left\{\ln \frac{\left(1-x^{0}\right)}{\left(1-x^{\mathrm{c}}\right)}+\frac{x^{0}}{\left(1-x^{0}\right)} \ln \frac{x^{0}}{x^{\mathrm{c}}}\right\}
$$

Combining Eqs. (5) and (6), the composition $x^{\mathrm{c}}$ is described as a function of $l, s$ and $\mathrm{d} l / \mathrm{d} t$ as follows.

$$
x^{\mathrm{c}}=\frac{x^{\mathrm{i}}}{\left(1+\frac{s l}{2 \delta D^{\mathrm{b}}} \frac{\mathrm{d} l}{\mathrm{~d} t}\right)}
$$

Inserting Eq. (15) into Eq. (14), we finally obtain the equation

$$
\begin{aligned}
\frac{\mathrm{d} l}{\mathrm{~d} t}= & \frac{M R T}{V_{\mathrm{m}}}\left\{1-\frac{x^{\mathrm{i}}}{\left(1+\frac{s l}{2 \delta D^{\mathrm{b}}} \frac{\mathrm{d} l}{\mathrm{~d} t}\right)}\right\} \\
\times & {\left[\ln \left(1-x^{0}\right)+\frac{x^{0}}{\left(1-x^{0}\right)} \ln \left\{\frac{x^{0}}{x^{\mathrm{i}}}\left(1+\frac{s l}{2 \delta D^{\mathrm{b}}} \frac{\mathrm{d} l}{\mathrm{~d} t}\right)\right\}\right.} \\
& \left.-\ln \left\{1-\frac{x^{\mathrm{i}}}{\left(1+\frac{s l}{2 \delta D^{\mathrm{b}}} \frac{\mathrm{d} l}{\mathrm{~d} t}\right)}\right\}\right] \ldots(16)
\end{aligned}
$$

If $M, \delta D^{\mathrm{b}}, V_{\mathrm{m}}$ and $x^{\mathrm{i}}$ are known and $s$ is described as a function of $t$ or $l$, i.e. $s(t)$ or $s(l)$ respectively, at a reaction temperature, we can find the relationship between $l$ and $t$ for DIR in the A(B) system, where the solute $\mathrm{B}$ diffuses into the binary $\mathrm{A}-\mathrm{B}$ solution phase, from Eq. (16).

\section{Analysis and Discussion}

\subsection{Growth Rate of DIR Region}

The kinetics of DIR in the $\mathrm{Fe}(\mathrm{Cu})$ system was experimentally studied by the present authors using the $\mathrm{Cu} /(\mathrm{Fe}-4.8 \mathrm{Cu}) / \mathrm{Cu}$ diffusion couples consisting of the pure $\mathrm{Cu}$ single crystals and the polycrystalline $\mathrm{Fe}$ phase specimens annealed at $1323 \mathrm{~K} .{ }^{1)}$ At this annealing temperature, the face-centered-cubic (f.c.c.) structure is stable for the Fe phase. During the annealing, fine grains with higher $\mathrm{Cu}$ concentration are formed from the in-

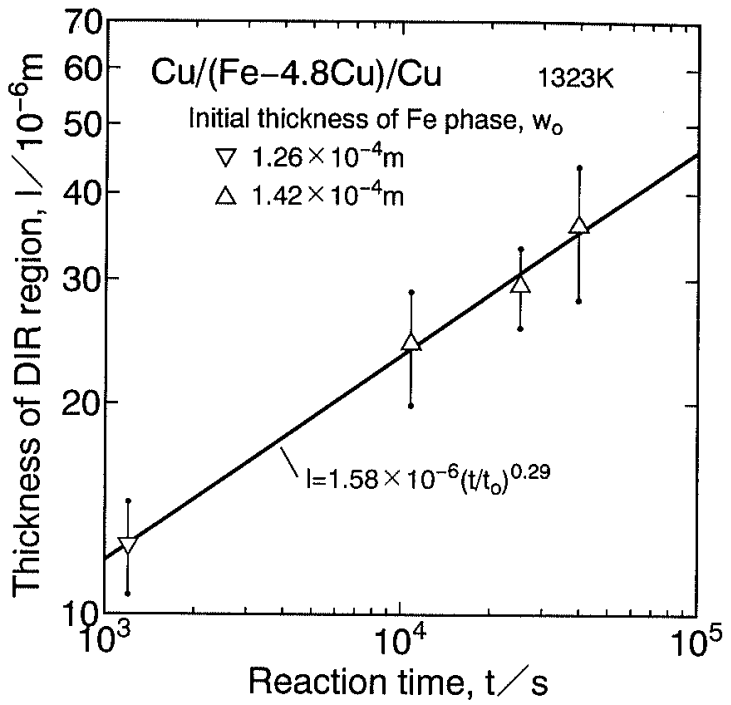

Fig. 2. The thickness / of the DIR region $v$ s. the reaction time $t$ observed by the present authors in the Fe phase of the $\mathrm{Cu} /(\mathrm{Fe}-4.8 \mathrm{Cu}) / \mathrm{Cu}$ diffusion couple annealed at $1323 \mathrm{~K}^{11}$

terfaces and grow into the f.c.c.-Fe phase due to DIR. An example of the observations is represented in Fig. 2. In this figure, the thickness $l$ of the DIR region is plotted against the reaction time $t$. The ordinate and the abscissa indicate the logarithms of $l$ and $t$, respectively. The average values of $l$ at the experimental reaction times are shown as open triangles. According to Fig. $2, l$ is expressed as a function of $t$ by the following equation.

$$
l=k\left(t / t_{0}\right)^{n}
$$

Here, $t_{0}$ indicates unit time, $1 \mathrm{~s}$, and is adopted to make the ratio $t / t_{0}$ dimensionless. Thus, the proportionality constant $k$ has the same dimension as the thickness $l$. The proportionality constant $k$ and the exponent $n$ were determined to be $1.58 \times 10^{-6} \mathrm{~m}$ and 0.29 , respectively, by a least square method from the experimental points in Fig. 2. Therefore, it is concluded that the thickness of the DIR region increases in proportion to the almost cubic root of the reaction time. Such kinetic behavior of DIR observed in the $\mathrm{Cu} /(\mathrm{Fe}-4.8 \mathrm{Cu}) / \mathrm{Cu}$ diffusion couple will be analyzed in this section.

The Li-Hillert model gives the relationship between the thickness $l$ and the reaction time $t$ through Eqs. (10) to (12). From Eq. (10), we obtain $\tau=4 \lambda$ for $\lambda \ll 1$ and thus

$$
\frac{l}{t}=\frac{M R T x^{\mathrm{i}}}{V_{\mathrm{m}}}
$$

for small values of $l$, whereas $\tau=\lambda^{2}$ for $\lambda \gg 1$ and consequently

$$
\frac{l^{2}}{t}=4 \sqrt{\frac{\delta D^{\mathrm{b}} M R T x^{\mathrm{i}}}{V_{\mathrm{m}}}}
$$

for large values of $l$. Equations (18) and (19) mean that $l$ increases in proportion to $t$ at early stages of the reaction, whereas $l$ increases proportionately with the square root of $t$ at late stages of the reaction. The experimental results in Fig. 2, however, indicate that $l$ 
increases in proportion to the almost cubic root of $t$. This kinetic behavior of DIR cannot be explained by the Li-Hillert model. As mentioned earlier, Eq. (10) describes the kinetics of the DIR, where the alloyed region grows into a pure metal. On the other hand, the DIR region with higher $\mathrm{Cu}$ concentration grows into the $\mathrm{Fe}-\mathrm{Cu}$ solution phase with lower $\mathrm{Cu}$ concentration in the experiment using the $\mathrm{Cu} /(\mathrm{Fe}-4.8 \mathrm{Cu}) / \mathrm{Cu}$ diffusion couple. In such a case, Eq. (16) should be used instead of Eq. (10). However, no analytical solution is known for Eq. (16). Thus, a numerical calculation technique ${ }^{11)}$ was utilized in this work.

According to the observations of DIR in the $\mathrm{Cu} /(\mathrm{Fe}-$ $4.8 \mathrm{Cu} / \mathrm{Cu}$ diffusion couple, ${ }^{1)}$ the concentration $x^{\mathrm{i}}$ of $\mathrm{Cu}$ at the interface in the DIR region coincides with the solubility $x_{\mathrm{Cu}}^{\gamma \alpha}$ of $\mathrm{Cu}$ in the f.c.c.-Fe phase at the reaction temperature ${ }^{12)}$ and is kept to be constant during the reaction. Therefore, the local equilibria between the $\mathrm{Fe}$ and $\mathrm{Cu}$ phases are considered to be realized for all the elements at the interface. Since the difference between the compositions in the DIR region and the untransformed matrix is rather small, $V_{\mathrm{m}}$ and $\delta D^{\mathrm{b}}$ are supposed to be constant at the reaction temperature. Assuming that the concentration profile of the solute along the stationary circular grain boundary is straight and thus $\mathrm{d} x / \mathrm{d} y=\left(x^{\mathrm{c}}-x^{\mathrm{i}}\right) / l, \mathrm{Li}$ and Hillert obtained Eq. (5). The boundary diffusion coefficient $\delta D^{\mathrm{b}}$ of $\mathrm{Cu}$ along a stationary grain boundary in f.c.c. $-\mathrm{Fe}$ is $\delta D^{\mathrm{b}}=4.26 \times 10^{-19} \mathrm{~m}^{3} / \mathrm{s}$ at $1323 \mathrm{~K}^{1{ }^{13)}}$ Using a value of $\delta=3 \times 10^{-10} \mathrm{~m}$, we obtain $D^{\mathrm{b}}=1.4 \times 10^{-9} \mathrm{~m}^{2} / \mathrm{s}$. The penetration distance $z$ of $\mathrm{Cu}$ along the grain boundary is estimated to be $z=1.3 \times 10^{-3}$ to $7.5 \times 10^{-3} \mathrm{~m}$ for $t=1.2 \times 10^{3}$ to $3.96 \times 10^{4} \mathrm{~s}$, respectively, by the relationship $z \approx \sqrt{D^{\mathrm{b}} t}$. On the other hand, the thickness $l$ of the DIR region varies from $l=1.3 \times 10^{-5}$ to $3.6 \times 10^{-5} \mathrm{~m}$ for $t=1.2 \times 10^{3}$ to $3.96 \times 10^{4} \mathrm{~s}$, respectively. Consequently, the ratio $z / l$ increases from 100 to 208 with increasing reaction time within the experimental reaction times. This means that the boundary diffusion of $\mathrm{Cu}$ along the circular grain boundary is considered fast enough to keep the concentration profile straight and thus Eq. (5) is valid. For the calculation, the mobility $M$ was chosen as the fitting parameter. The value of $M$ was determined to minimize the parameter $S$ defined as

$$
S=\sum_{i=1}^{n}\left(l_{i}^{\text {exp }}-l_{i}^{\mathrm{cal}}\right)^{2}
$$

Here, $l_{i}^{\text {cal }}$ and $l_{i}^{\text {cxp }}$ are the calculated and experimentally determined thicknesses, respectively, of the DIR region at each experimental reaction time $t_{i}$. The following values were used for the calculation at $1323 \mathrm{~K}$ and then the value of $M=8.64 \times 10^{-13} \mathrm{~m}^{4} / \mathrm{J} \mathrm{s}$ was obtained: $\delta D^{\mathrm{b}}=$ $4.26 \times 10^{-19} \mathrm{~m}^{3} / \mathrm{s},{ }^{13)} V_{\mathrm{m}}=7.096 \times 10^{-6} \mathrm{~m}^{3} / \mathrm{mol}^{14)} x^{\mathrm{i}}=$ $x_{\mathrm{Cu}}^{\gamma \alpha}=0.0615^{12)}$ and $x^{0}=x_{\mathrm{Cu}}^{0 \gamma}=0.0424 .^{1)}$ Using this value of the mobility, the thickness $l$ of the DIR region was calculated as a function of the reaction time $t$. The result is shown as a solid curve in Fig. 3. In this figure, the experimental points in Fig. 2 are also represented as open triangles. Although only the mobility $M$ in Eq. (16) is used as the fitting parameter, the calculation well coincides with the experimental points within experi-

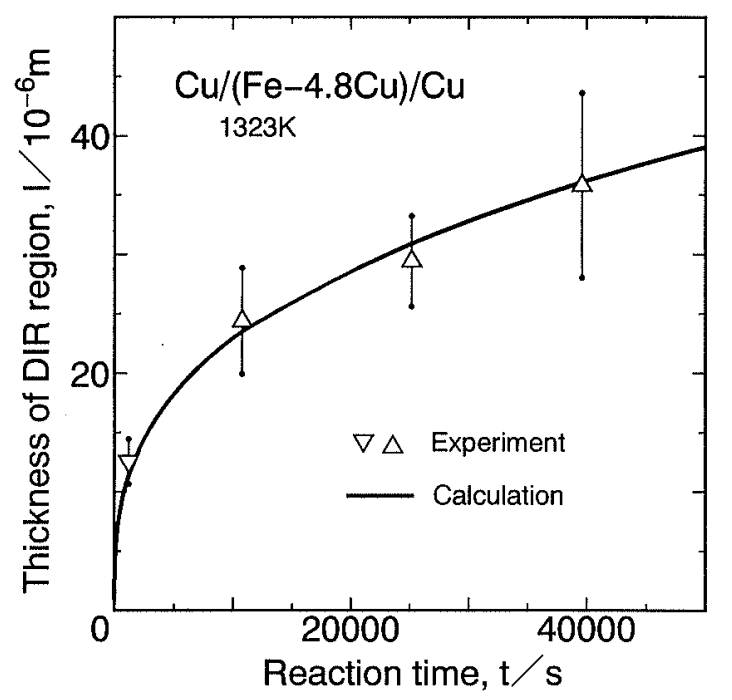

Fig. 3. The thickness $/$ of the DIR region $v s$, the reaction time $t$ calculated by Eq. (16). The experimental points in Fig. 2 are also shown.

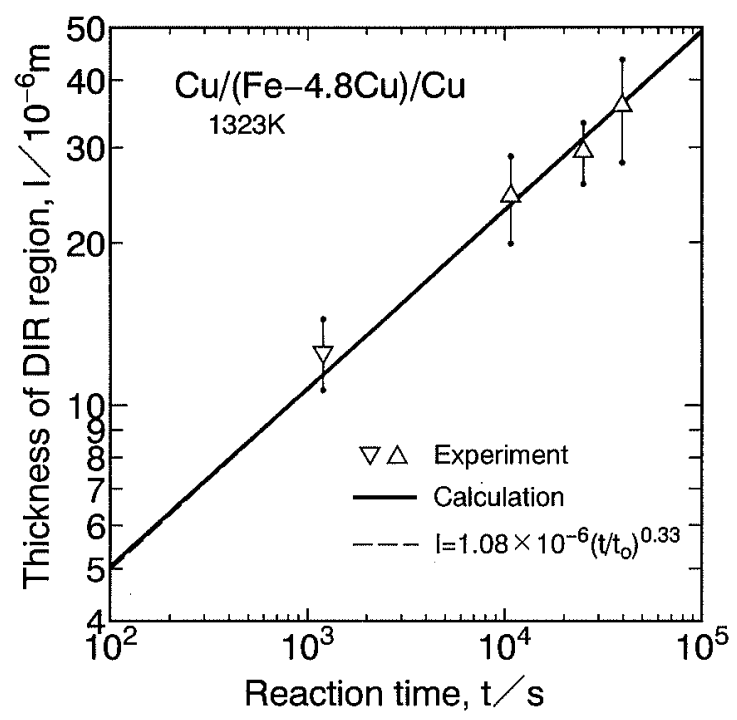

Fig. 4. The replotting of Fig. 3, showing the relationship between $l$ and $t$ calculated by Eq. (16).

mental accuracy as can be seen in Fig. 3. The results in Fig. 3 are plotted in the logarithm scales in Fig. 4. As shown in this figure, the calculated curve becomes almost straight at reaction times longer than $5 \times 10^{2} \mathrm{~s}$. The straight part of the curve is described by Eq. (17) with the parameters of $n=0.33$ and $k=1.08 \times 10^{-6} \mathrm{~m}$. A broken line in Fig. 4 indicates the calculation using these parameters. Consequently, it is concluded that the growth rate of the DIR region growing into a pure metal obeys the square root law whereas that of the DIR region growing into a binary solution obeys the cubic root law at late stages of the reaction.

\subsection{Composition Dependence of Kinetic Behavior of DIR}

According to the conclusions mentioned in Sec. 3.1, the existence of solute atoms in the untransformed matrix changes the kinetic behavior of DIR from the square root law to the cubic root law at late stages of the reaction. In order to estimate the effect of the solute on the 
kinetic behavior of DIR, the thickness of the DIR region was calculated as a function of the reaction time for various values of the initial concentration $x^{0}$ of the solute in the untransformed matrix by Eq. (16) using the same values of the parameters as Sec. 3.1. The results are shown as solid curves in Fig. 5. As $x^{0}$ decreases, the chemical driving force $\Delta G_{\mathrm{m}}^{\mathrm{c}}$ increases through Eq. (13) and thus the migration rate $\mathrm{d} l / \mathrm{d} t$ of the moving grain boundary increases according to Eq. (1) as can be seen in Fig. 5. For all the values of $x^{0}$ in Fig. 5, the calculated curve becomes almost straight at late stages of the reaction. At the late stages, the exponent $n$ takes a value of $n=$ 0.33 between $x^{0}=0.01$ and 0.05 whereas it slightly increases to $n=0.34$ at $x^{0}=0.001$. This means that the kinetic behavior of DIR obeys the cubic root law even in a solution phase with very small concentrations of the solute. When $x^{0}=0, n$ becomes equal to 0.5 and thus both the $\mathrm{Li}$-Hillert and present models give the same

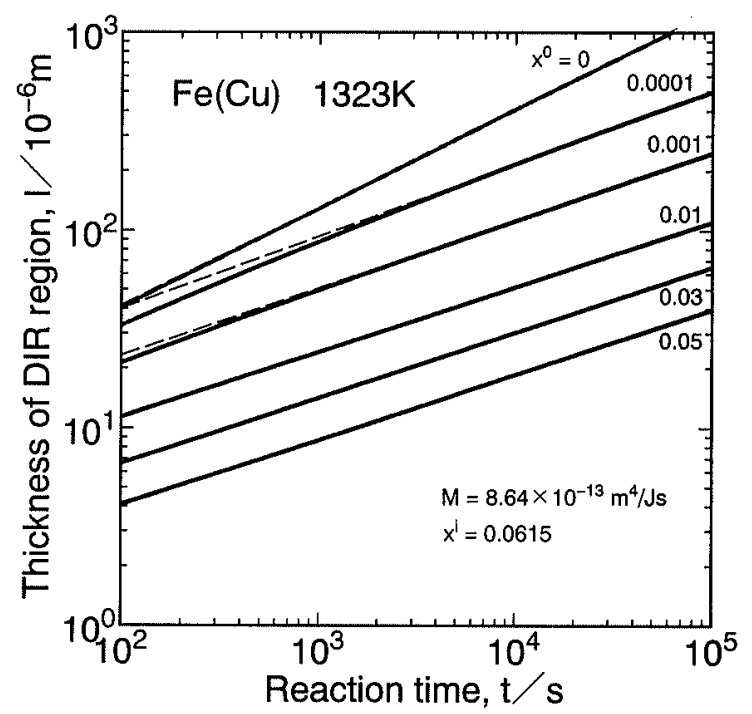

Fig. 5. The thickness $l$ of the DIR region $v s$. the reaction time $t$ calculated by Eq. (16) for various values of the initial concentration $x^{0}$ of $\mathrm{Cu}$ in the untransformed Fe matrix for DIR in the $\mathrm{Fe}(\mathrm{Cu})$ system at $1323 \mathrm{~K}$.

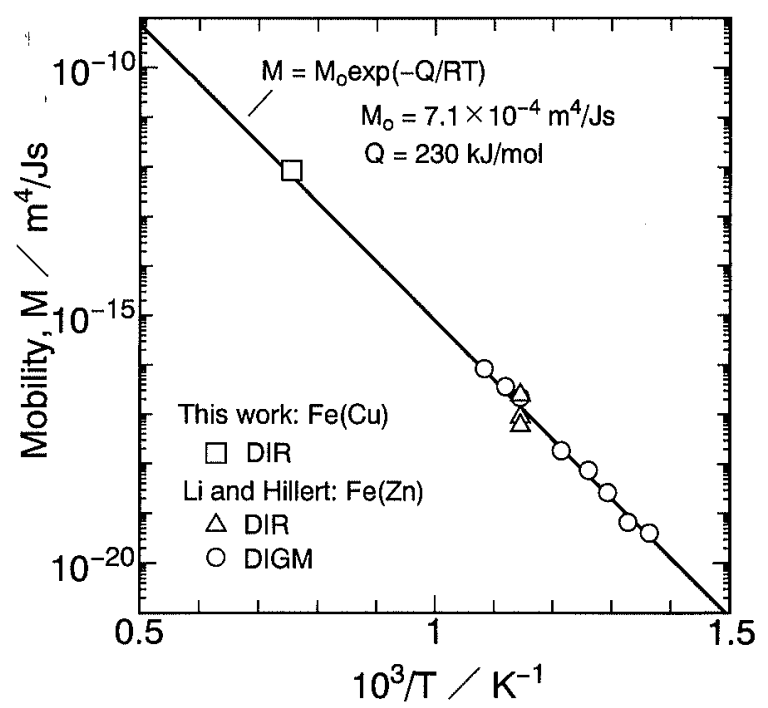

Fig. 6. The logarithm of the mobility $M v s$. the reciprocal of the absolute temperature $T$ for DIR in the $\mathrm{Fe}(\mathrm{Cu})$ system. The results obtained by $\mathrm{Li}$ and Hillert ${ }^{5)}$ for DIR and DIGM in the $\mathrm{Fe}(\mathrm{Zn})$ system are also shown. kinetic behavior of DIR.

\subsection{Mobility}

The mobility $M$ in Eq. (16) was chosen as the fitting parameter for the calculation in Fig. 3 and determined to be $M=8.64 \times 10^{-13} \mathrm{~m}^{4} / \mathrm{J}$ s at $1323 \mathrm{~K}$ from the experimental data. This value is shown as an open square in Fig. 6. In this figure, the ordinate and the abscissa indicate the logarithm of the mobility and the reciprocal of the absolute temperature, respectively. Li and Hillert ${ }^{5)}$ evaluated the mobility for DIR and DIGM in the $\mathrm{Fe}(\mathrm{Zn})$ system from the experimentally determined composition in the alloyed region and the migration rate of the moving grain boundary at temperatures between 733 and $923 \mathrm{~K}$. At this temperature range, the body-centered-cubic (b.c.c.) structure is stable for the $\mathrm{Fe}$ phase. Their values of the mobility for DIR and DIGM are also plotted as open triangles and circles, respectively, in Fig. 6. As can be seen in Fig. 6, their values are well located on a straight line. If the straight line is expressed by the equation

$$
M=M_{0} \exp \left(-\frac{Q}{R T}\right)
$$

we obtain $M_{0}=7.1 \times 10^{-4} \mathrm{~m}^{4} / \mathrm{J}$ s and $Q=230 \mathrm{~kJ} / \mathrm{mol}$ by a least square method. These values of $M_{0}$ and $Q$ give the extrapolated value of $M=5.9 \times 10^{-13} \mathrm{~m}^{4} / \mathrm{J} \mathrm{s}$ at $1323 \mathrm{~K}$. This value almost coincides with the value of $M=8.64 \times 10^{-13} \mathrm{~m}^{4} / \mathrm{J} \mathrm{s}$ obtained in this work for DIR in the $\mathrm{Fe}(\mathrm{Cu})$ system.

The mobility of the moving grain boundary for DIR and DIGM is relevant to the solute drag effect on the moving grain boundary. The solute drag may be controlled by the grain boundary diffusion of solute atoms across the moving grain boundary and/or the volume diffusion of the solute atoms along the moving direction in the untransformed and alloyed matrices near the moving grain boundary. The value of $Q=230 \mathrm{~kJ} / \mathrm{mol}$ is greater than the activation enthalpy of $177-195 \mathrm{~kJ} / \mathrm{mol}$ for grain boundary diffusion ${ }^{15}$ but close to the one of $233 \mathrm{~kJ} / \mathrm{mol}$ for volume diffusion of $\mathrm{Zn}$ in b.c.c.- $\mathrm{Fe}{ }^{16}$ ) Thus, the volume diffusion seems to play the most important role in the solute drag effect for DIR and DIGM in the $\mathrm{Fe}(\mathrm{Zn})$ system.

DIR and DIGM in the $\mathrm{Fe}(\mathrm{Zn})$ system were observed in the b.c.c.-Fe phase by $\mathrm{Li}$ and Hillert, whereas DIR in the $\mathrm{Fe}(\mathrm{Cu})$ system was found in the f.c.c.-Fe phase by the present authors. The volume diffusion coefficient of $\mathrm{Cu}$ in f.c.c. $-\mathrm{Fe}, D_{\mathrm{Cu}}^{\gamma \mathrm{Fe}}$, is $3.8 \times 10^{-16} \mathrm{~m}^{2} / \mathrm{s}$ whereas that of $\mathrm{Zn}$ in b.c.c. $\mathrm{Fe}, D_{\mathrm{Zn}}^{\alpha \mathrm{Fe}}$, is $1.5 \times 10^{-13} \mathrm{~m}^{2} / \mathrm{s}$ at $1323 \mathrm{~K} .{ }^{16)}$ Therefore, $D_{Z_{\mathrm{n}}}^{\alpha \mathrm{Fe}}$ is about 400 times greater than $D_{\mathrm{Cu}}^{\gamma \mathrm{Fe}}$ at this temperature. The greater the diffusion coefficient is, the smaller the solute drag effect can be and thus the greater the mobility might become. However, the extrapolated value of $M=5.9 \times 10^{-13} \mathrm{~m}^{4} / \mathrm{J} \mathrm{s}$ for DIR and DIGM in the b.c.c.-Fe phase of the $\mathrm{Fe}(\mathrm{Zn})$ system is close to the value of $M=8.64 \times 10^{-13} \mathrm{~m}^{4} / \mathrm{J} \mathrm{s}$ obtained for DIR in the f.c.c.-Fe phase of the $\mathrm{Fe}(\mathrm{Cu})$ system at $1323 \mathrm{~K}$ as mentioned earlier. In order to discuss the absolute values of the mobility in detail, the solute drag effect is needed to be analyzed quantitatively. 


\section{Conclusions}

A new kinetic equation was obtained for DIR in the $A(B)$ system, where the solute $B$ diffuses into the binary $\mathrm{A}-\mathrm{B}$ solution phase, combining the columnargeometry and boundary-diffusion model by Li and Hillert with the energy balance model by Kajihara and Gust. The kinetic equation was utilized to analyze the kinetic behavior of DIR in the $\mathrm{Fe}(\mathrm{Cu})$ system observed by the present authors using the $\mathrm{Cu} /(\mathrm{Fe}-4.8 \mathrm{Cu}) / \mathrm{Cu}$ diffusion couple consisting of the pure $\mathrm{Cu}$ single crystals with the same crystallographic orientation and the polycrystalline Fe phase specimen annealed at $1323 \mathrm{~K}$. According to the observations, the regions alloyed with $\mathrm{Cu}$ are formed from the interfaces and grow into the $\mathrm{Fe}$ phase due to DIR. The thickness $l$ of the DIR region increases with increasing annealing time $t$ according to the relationship $l=1.58 \times 10^{-6}\left(t / t_{0}\right)^{0.29}$. Here, $l$ and $t$ are measured in $\mathrm{m}$ and $\mathrm{s}$, respectively, and $t_{0}$ is unit time, $1 \mathrm{~s}$. The new kinetic equation could quantitatively account for this relationship. The analysis indicates that at late stages of the reaction the thickness of the DIR region increases in proportion to the square root of the annealing time when DIR occurs in a pure metal whereas that of the DIR region increases proportionately with the cubic root of the annealing time if DIR takes place in a binary solution phase.

\section{Acknowledgement}

This work was supported by an ISIJ Research
Promotion Grant from the Iron and Steel Institute of Japan.

\section{REFERENCES}

1) Y. Kawanami, S. Yoshida, N. Takeuchi, M. Kajihara and T. Mori: ISIJ Int., 37 (1997), 590.

2) Y. Kawanami, M. Kajihara and T. Mori: CAMP-ISIJ, 8 (1995), 1383.

3) Y. Kawanami, M. Kajihara and T. Mori: Proc. Annual Meeting Jpn. Inst. Met., Jpn. Inst. Met., Sendai, (1996), 426.

4) Y. Kawanami, M. Nakano, M. Kajihara and T. Mori: Proc. Annual Meeting Jpn. Inst. Met., Jpn. Inst. Met., Sendai, (1996), 427.

5) Li Chongmo and M. Hillert: Acta Metall., 29 (1981), 1949.

6) M. Hillert and G. R. Purdy: Acta Metall., 26 (1978), 333.

7) M. Kajihara and W. Gust: Acta Metall. Mater., 39 (1991), 2565

8) M. Kajihara and W. Gust: Acta Mater., submitted.

9) R. A. Fournelle: Mater. Sci. Eng., A138 (1991), 133.

10) M. Hillert: Scr. Metall., 17 (1983), 237.

11) T. S. Parker and L. O. Chua: Practical Numerical Algorithms for Chaotic Systems, Springer-Verlag, Inc., New York, (1989), 83.

12) Binary Alloy Phase Diagram, Vol. 2, ed. by Massalski et al., ASM International, Ohio, (1990), 1409

13) V. A. Lazarev and V. M. Golikov: Phys. Met. Metall, 31 (1971) 212.

14) Metals Data Book, ed. by Japan Inst. Metals, Maruzen, Tokyo, (1993), 10

15) I. Kaur and W. Gust: Handbook of Grain and Interphase Boundary Diffusion Data, Vol. 2, Ziegler Press, Stuttgart, (1989), 857.

16) Metals Data Book, ed. by Japan Inst. Metals, Maruzen, Tokyo, (1993), 22. 